\title{
645
}

\section{THE NEED OF FERTILIZERS IN THE ARID WEST}

GERMAN KALI WORKS 

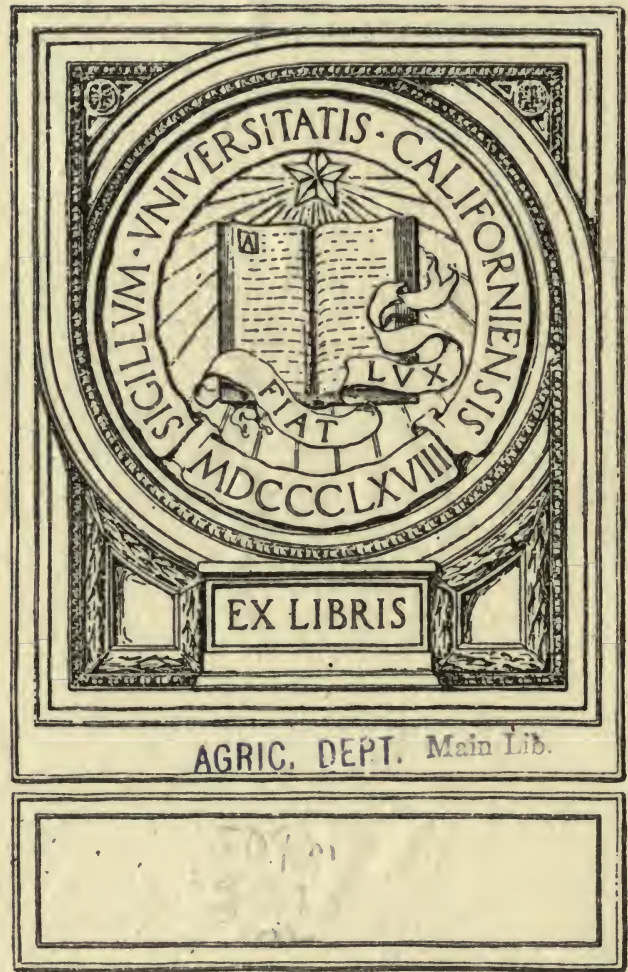

Digitized by the Internet Archive in 2007 with funding from Microsoft Corporation 


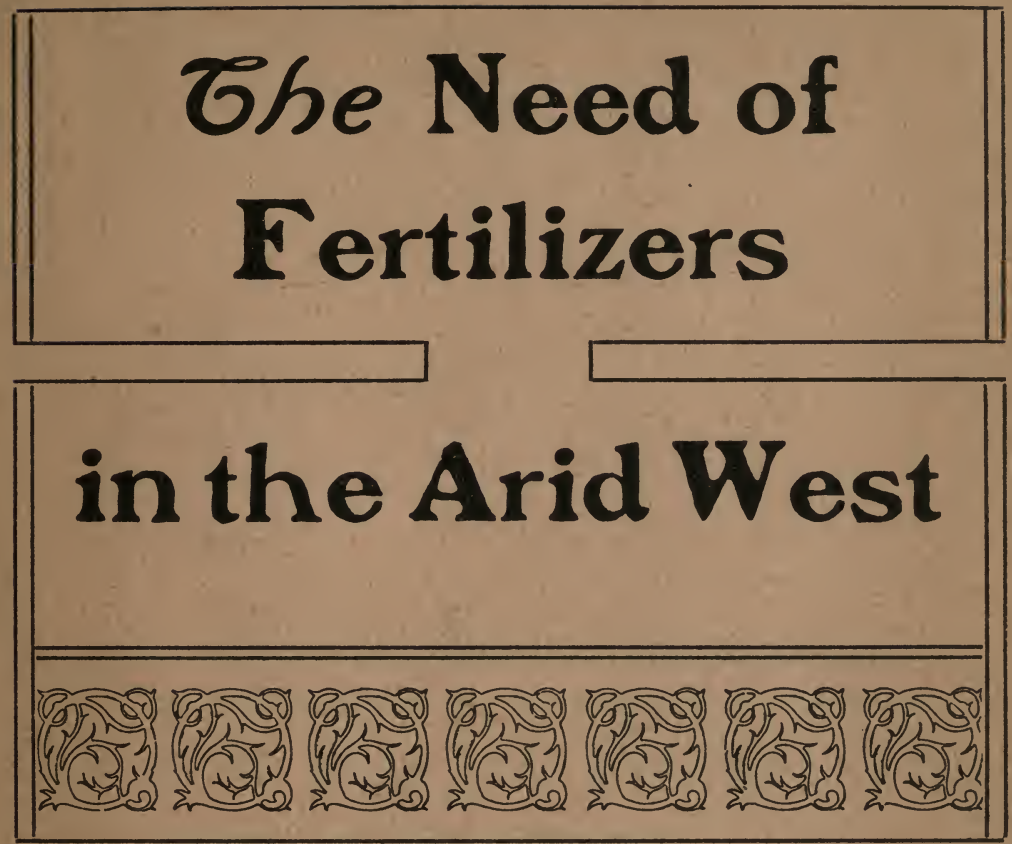




\section{The Need of Fertilizers}

\section{in the Arid West}
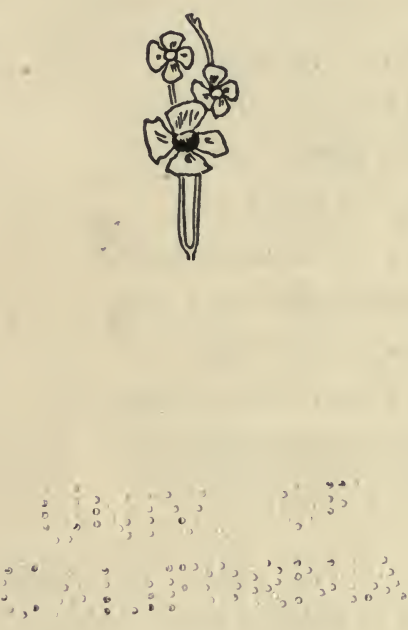

PUBLISHED BY

\section{GERMAN KALI WORKS}

New York, N. Y.

Chicago, Ill.

Atlanta, Ga.

New Orleans, La.

San Francisco, Cal. 


\section{$\underline{\text { NOTICE }}$}

\section{S6+5}

Every farmer can obtain, free of charge, a copy of the following agricultural books :

POTASH IN AGRICULTURE

PRINCIPLES OF PROFITABLE FARMING

TRUCK FARMING

PLANT FOOD

THE COW PEA

COTTON CULTURE

SUGAR CANE CULTURE

SUGAR BEET CULTURE

TOBACCO CULTURE

VALUE OF SWAMP LAND

STRAWBERRY CULTURE

ORANGE CULTURE

WHY THE FISH FAILED

FERTILIZING PEACHES

FERTILIŻlNG FRUTSS: $: \vdots: \vdots$

State which the the :abovie mentioned publications you desire, and it will be mailed to you free of charge.

ADDRESS:

\section{GERMAN KALI WORKS}

NEW YORK, N. Y.

42 Broadway
CHICAGO, ILL, 1901 McCormick Bldg.
ATLANTA, GA. 1212 Empire Bldg.
NEW ORLEANS, LA. 903 Whitney-Central Bldg.
SAN FRANCISCO, CAL. 25 California St. 


\section{Fertilizers, What They Are and What They Are Good For.}

While "fertilizer" has become a household word in the humid sections of the United States, it is practically unknown in the arid and semi-arid districts of the West. This, in part at least, is due to the fact that these regions have only in recent times been opened to general farming, and that the freight rates to most of these points west make the purchase of commercial fertilizers too costly at present. There are some other reasons, however, which will be fully discussed further on.

Since fertilizers are so little known in the regions of low rainfall, it will not be out of place here to give a few explanations in regard to their nature and use. It is a well established and undisputed fact that plants, just as well as animals, cannot grow from nothing. While no farmer would ever be so foolish as to withhold food from his stock and let it starve, there are still many farmers that will leave it to the plant to get its food supply as best it can. Everyone knows that if he wants to get top prices for his cattle, he must fatten them up and must let them have plenty of food for this end. The same is true of plants. You may grow some kind of a crop on almost any land if you give it a little care, but if you want to grow a good crop and plenty of it you must not leave all the work of producing it to the soil alone, lest it go back on you in a short while. 
In order to be able to grow, the plant, in addition to the water and the carbon dioxide taken from the atmosphere, extracts from the soil a large amount of material to build up its tissues. When the crop is sold all this material taken from the soil is removed with it and is forever lost. . It is true that all ordinary soils are immensely rich in some food elements needed by plants, and that they are practically inexhaustible in these. But there are just three elements; potash, phosphorus and nitrogen, that are of the greatest importance to the plant, and it is exactly these same three elements which are asually found in soils in only small quantities, and unfortunately by far the larger portion of them is in such a state of combination that the plant cannot get hold of them. It is only logical that if you do not want to rob your soil and if you wish to maintain or increase its fertility you must put back into it whatever your crop has removed. Otherwise your soil is bound to run down quickly. If you continuously draw money from your bank and make no deposits, your account will soon be exhausted. The same is true of the plant food elements in the soil.

Take for instance oats, wheat or potatoes. A sixty bushel crop of oats removes from the soil 55 pounds of nitrogen, 22 pounds of phosphoric acid and 62 pounds of potash, while a thirty-five bushel crop of wheat removes, 59 pounds, 24 pounds and 31 pounds, respectively, and a two hundred bushel crop of potatoes, 46 pounds, 21 pounds and 74 pounds. In order to compensate for these losses, every farmer should add to his soil at least those quantities of the different elements that are taken out of the soil. 
All of the three elements, nitrogen, phosphoric acid and potash together are necessary for the successful production of crops and no one of them can take the place of any other, because each one of them has important well defined functions. For this reason any fertilizer should, in all but exceptional cases, contain nitrogen as well as phosphoric acid and potash in suitable proportions. In looking closer over the figures given above it is easily seen that phosphoric acid is the ingredient needed in the smallest quantity, whereas the necessary amounts of potash and nitrogen are much higher.

Each of the three fertilizer elements has special functions to perform which may be mentioned briefly as follows:

Nitrogen increases growth and favors the formation of the green parts of plants, like stems and leaves. It is the factor that exerts the greatest influence on the size of the plant. The effect of an application of soluble nitrogen manifests itself in a few days by a change of the color of the leaves to a dark green. For the reason given, large quantities of nitrogen are called for particularly, where leaves are the principal product, like in the case of certain graden crops, where it also improves the quality by making the leaves more tender and crisp. On the other hand, where the fruit is the important product, too large applications of nitrogen are liable to bring about excessive growth of leaves, to delay or prevent the formation of flowers and fruit, and to retard maturity in general. Plants that are overfed with nitrogen, have a tendency to be soft and to be less resistant to the attacks of insects and diseases.

Phosphorus is an important constituent of the plant cell, especially of certain proteid bodies characteristic of all seeds, 
and for this reason alone a good supply of phosphoric acid is necessary for the production of all plants and fruits. It stimulates the growth of seedlings, favors the formation of fruit and brings about early maturity. In this respect its effect is opposite to that of nitrogen.

Potash is very important in regulating the vegetative functions of the plant in a chemical and mechanical way, being found in largest amounts at those points where actual development is proceeding most rapidly. Potash is essential to the formation of the so-called carbohydrates, sugar, starch, and cellulose, and to the transformation of sugar into starch and vice versa, without which vegetation could not exist. The importance of these effects of potash is at once understood if we consider that starch and sugar are the principal plant constituents used as food for man and beast. Starch is the chief component of potatoes, of corn and of the different cereals, and sugar that of the sugar cane and sugar beet. The formation of cellulose is essential to that of wood, and a lack of potash manifests itself by the weakness and brittleness of the woody parts of plants; this is of especial importance in fruit growing. Here potash has the additional advantage that it improves the quality of fruits, by making them more fleshy and of better flavor. Fruit grown with the required amount of potash also keeps and stands shipment better than otherwise. Potash is of the greatest benefit in the production of legumes and also of grasses where it favors the formation of seed. It also renders plants more hardy and more resistant to the attacks of insects and diseases. 


\section{Sources of the Fertilizer Elements.}

Nitrogen:- This element can be supplied in two different ways. The first and cheaper of these is to grow leguminous crops like alfalfa, clover or cowpeas on the land. These plants have the power of extracting nitrogen from the air, and of accumulating it. By then turning the crops under, either wholly or in part, all or the greater portion of this nitrogen is saved. Moreover, in this way we do not only supply nitrogen to our land, but incorporate with it that indispensible organic material necessary for the formation of humus. Humus is essential in the conservation of the soil moisture.

The second way of supplying nitrogen is by adding it in the form of some commercial, nitrogenous fertilizer, like nitrate of soda, sulfate of ammonia, cyanamid, dried blood, cotton seed meal, etc. If nitrogenous fertilizers must be bought, it will be best in the West to use those which have a high percentage of nitrogen, in order to save freight.

Phosphoric Acid:-There are several forms in which this fertilizer element can be supplied, Some phosphate fertilizers, such as acid phosphate and dissolved bone are easily soluble and can be utilized immediately by the plants. Others are less available and their assimilation by the crop is much slower than in the case of the first two. Among these fertilizers we mention Thomas slag and bone meal. The least available of the common phosphate fertilizers is ground rock phosphate; this is quite insoluble and it is effective only if applied together with large quantities of stable or green manure. The acids formed by the decomposition of the 
manure slowly liberate phosphoric acid from the rock phosphate and thus make it available.

Potash :-The only commercially important source of this fertilizing element are the German potash mines which furnish potash in a water soluble and immediately available form. The crude salts, kainit and manure salt, containing 12.4 and 20 per cent of pure potash, respectively, are largely used where freight rates are low or where they offer special advantages, as kainit does as a remedy against cotton rust. Muriate of potash and sulphate of potash contain about 50 per cent of pure potash; the muriate may be used for most crops, while the sulphate is preferable for tobacco, orange trees and potatoes.

In consideration of the fact that potash, phosphoric acid and nitrogen are of so much importance in the nutrition of plants it is not to be wondered at that their use in the form of fertilizers has given such excellent results wherever the right kind of fertilizer has been given a fair trial. In the following chapters we shall demonstrate by the results of actual field experiments that fertilizers are just as necessary and as profitable in regions of low rainfall as they are in the humid zone.

\section{Fertilizers Are Profitable in Dry Regions as Well as in Humid Sections.}

There is an idea generally prevailing in the Western States that while it may be profitable and necessary to use commercial fertilizers in the humid sections of the country, no 
results can be expected from their use in the arid and semiarid districts of the West. This belief seems to be based more on theoretical considerations than on practical experience. An inquiry made by writing to the experiment stations located in the sub-humid zone with the object of finding out what has so far been done towards studying the use of commercial fertilizers there, has brought out the fact that with a few notable exceptions, the different stations have not yet taken up the study of this question.

Although the few experiment stations that have experimented with commercial fertilizers have found that it is profitable to apply them even where the rainfall is low, the consensus of opinion still seems to be that they cannot be used to advantage. Two reasons are usually given for this idea. The first is, that the soils of these regions are generally classed as soils rich in plant food, especially so in phosphoric acid and potash. The nitrogen is rather low, but it is, according to Hilgard, available to a much larger degree than that found in soils of the humid zone. However, from the comparatively large percentages of phosphoric acid and potash as found by chemical analysis, we are not justified to conclude that the soils are rich in these elements as far as the needs of plants are concerned, because as a rule most of this plant food in the soil is insoluble and cannot be assimilated by growing crops fast enough to provide for the most profitable crops.

Soil analysis, as practiced at present, discloses only that portion of the elements of plant food that may be liberated within the next thousand or ten thousand years, provided 
that conditions are favorable. But this knowledge is of little practical value, because plant food liberated in a thousand years is of no use to us; and besides, we are in honor bound to pass on our land to our sons and grandsons in at least the same state of fertility in which we received it ourselves. For these reasons we should and must return to the soil, no matter how rich our land is or how much rainfall we have, the potash, phosphoric acid and nitrogen that we have removed from it by cropping, if we want to at least maintain the fertility of our land. But the intelligent and progressive farmer will not stop here; he is not satisfied with just maintaining the fertility of his soil, but constantly strives to attain that point where a given acre yields him the largest possible profit. This cannot be done without adequate fertilization.

The other assertion advanced to discredit the use of commercial fertilizers in the arid and semi-arid regions of the West is to the effect that the amount of moisture in our western soils is not sufficient to allow of the proper utilization of the fertilizer applied. This is true only insofar as slightly more water is necessary for the production of the increased crop raised with the aid of fertilizer, than for the small crop grown without it. But the fertilizer as such does not only not reduce the moisture present in your soil, but on the contrary helps to conserve this moisture. This has been amply demonstrated by scientific experiments as well as by practical experience. Dr. John A. Widtsoe, the well-known president of the Utah Agricultural College, who has made a large number of careful experiments on this question, came to the conclusion that "the application of artificial fertilizers to a soil which 
requires them will not only increase the yield of dry matter: but will make it possible for plants to produce dry matter at a lower water cost than on similar soils which have not received such artificial stimulus. This is a vital matter in the agriculture of a region where water is an essential consideration." Even on clay soils "the addition of fertilizers increased the yield in every case. With the complete fertilizer the increase was over six times the yield on the unfertilized pot. The total number of pounds of water required to produce one pound of dry matter was likewise in every case very much smaller on the fertilized than on the unfertilized pots."

Practical experience has shown the conclusion of Dr. Widtsoe to hold true under field conditions. Dr. R. W. Thatcher, director of the Washington State Experiment Station, states the following:

"So far as can be determined by chemical analysis the typical basaltic loam soils of Southeastern Washington, the so-called 'volcanic ash' soils, contain ample supplies of the most essential forms of plant food for large cereal and forage crops for many years to come. It has been demonstrated, however, that where the moisture supply is limited, as it is throughout the non-irrigated districts of Eastern Washington, crops can frequently make much better use of the soil moisture if increased supplies of available plant food are furnished to them. For this reason, it is sometimes profitable to use fertilizers even if the soil does contain a large supply of total plant food."

Dr. Thatcher then advises the farmers to make practical field experiments with fertilizers and to find out for themselves. 
The few isolated experiments made with commercial fertilizers under irrigation and dry farming conditions in Washington, California, Colorado and New Mexico have demonstrated that it is indeed profitable to use commercial fertilizers in those States. Considerable quantities of fertilizers are already being used in onion culture around Laredo, 'Texas, and some in alfalfa culture in other parts of Texas. The Arizona Experiment Station recommends the use of commercial fertilizers on orange trees.

The results obtained with commercial fertilizers so far in the States just mentioned above certainly ought to encourage their use in the West, and should stimulate further efforts in the same direction. This is all the more important, since in other countries of low rainfall, which we are otherwise apt to look upon as less advanced than our country, have long since learned to appreciate the great value of commercial fertilizers for not only increasing the yield and improving the quality of their products, but at the same time enhancing the fertility of their soil.

The table below shows the results of systematic experiments made with complete fertilizers containing potash, phosphoric acid and nitrogen, by the Central Office of Fertilizer Experiment Stations in Madrid, Spain. We produce here only a few of the thirty odd experiments made in the dry districts of Spain. 


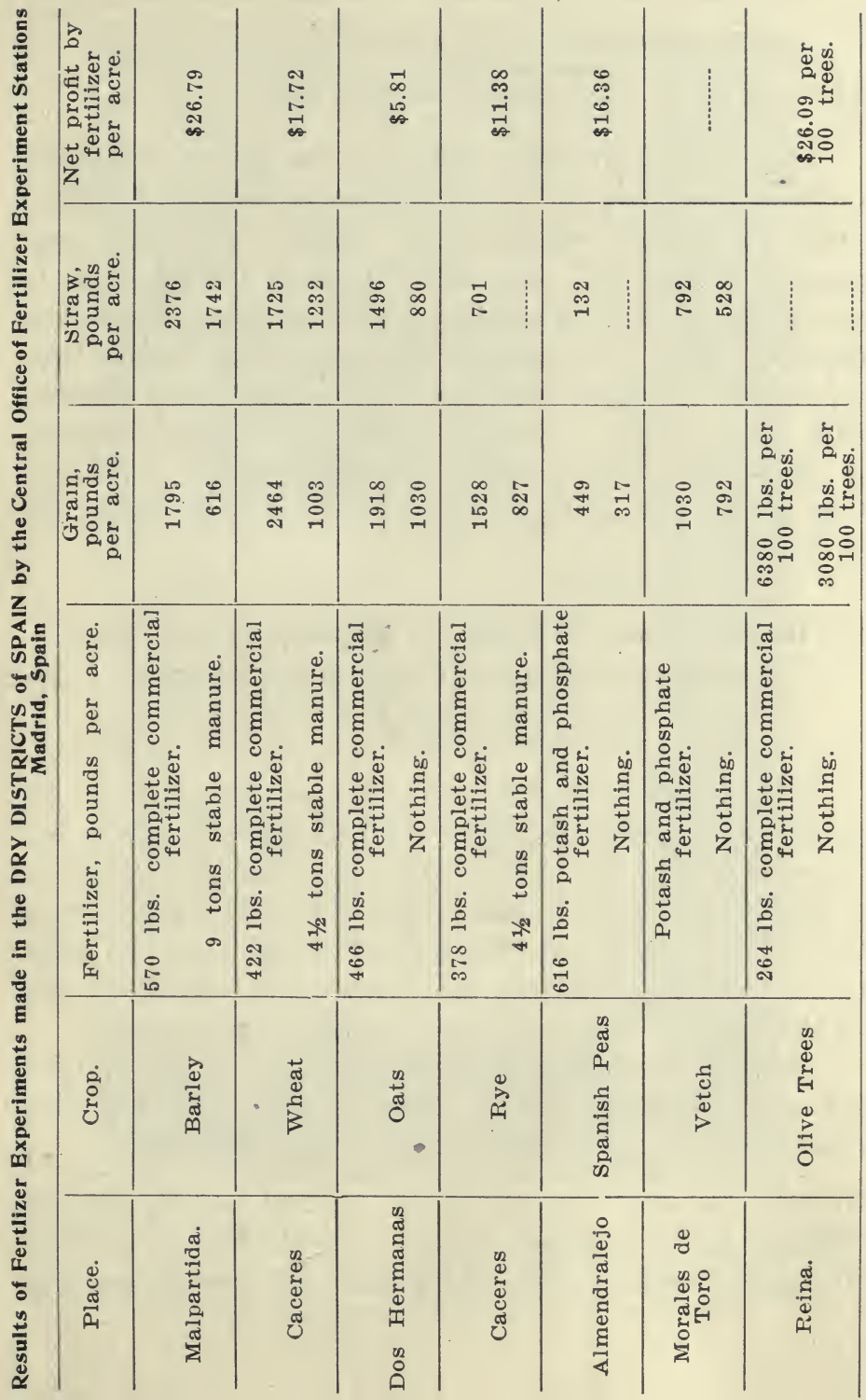


One would have to be blind not to see the large monetary profits derived from the use of complete commercial fertilizers under the very dry conditions of Spain. But the most remarkable result of these experiments is the fact that in several of the tests the check plot received heavy applications of stable manure. In spite of all this the profits derived from commercial fertilizers were much larger than those obtained with stable manure. 'This refutes the popular belief prevalent in some of the Western States that stable manure is the only hope to the farmer there, when it comes to increasing his crop yields.

\section{The Fertilizer, to Yield the Highest Profit, Must Contain a Sufficient Percentage of Potash.}

It has been remarked above that our western soils are generally rich in total potash and that this misleading fact is responsible for the theory that potash would not prove profitable there as a fertilizer ingredient. The only way to decide this question is by practical field experiments. A number of such tests have been made in the Canadian West, and we shall mention here only two of them:

Mr. L. M. McLean, Innisfail, Alberta, Canada, carried out one such experiment on potatoes, with the following results :

No fertilizer 280 bushels per acre

Nitrogen and Phosphoric Acid 312 bushels per acre Nitrogen, Phosphoric Acid and Potash ...409 bushels per acre 


\section{Potato Experiment by L. W. McLEAN, Innisfail, Alta.}

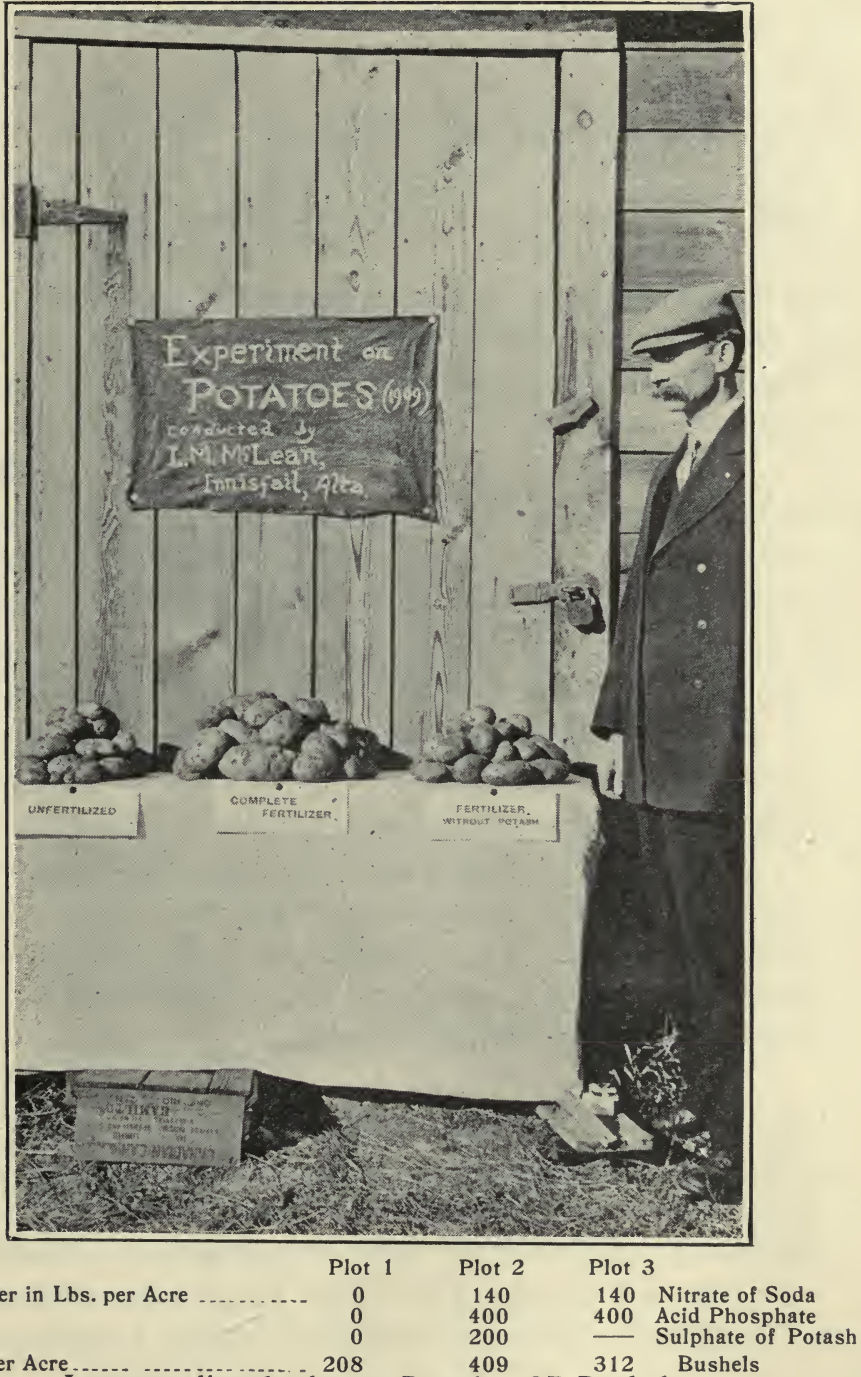

Yield per Acre ................... 208 Increase directly due to Potash: 97 Bushels. 

In other words, 200 pounds of potash produced an increase of ninety-seven bushels per acre. The net profit per acre due to potash alone after deducting the cost of the same amounted to $\$ 2 \% .96$.

In the light of these figures, does it seem profitable to use potash or not? Let us cite another example. The crop in this case was cabbage, and the farmer who made the experiment was Mr. John de Jong, Louise Bridge, Manitoba, Canada :

No fertilizer ........................................................... 32,500 pounds

Nitrogen and Phosphoric Acid ……......................37,500 pounds Nitrogen, Phosphoric Acid and Potash ................40,000 pounds

In this case, the net profit due to potash after deducting the cost of the fertilizer was $\$ 3 \% .00$. In another experiment as much as $\$ 47.71$ profit was made by using potash in the fertilizer.

But Canada is not the only country where such striking increases in yields have been obtained with potash.

A very extended study on the effect of potash as a fertilizer on wheat and other cereals, under dry farming conditions, has been made by Mr. J. Farges, professor of Agriculture at Philippeville, Algiers. He arrived at the following conclusions :

"It is well-known that potash, the same as nitrogen and phosphoric acid, is indispensible for all plants. But potash is particularly essential for those plants which furnish starch, as for instance, the cereals. In fact, it has been irrefutably demonstrated that starch cannot be produced by sunlight unless a sufficient quantity of potash be present.... Experience 
has shown that those crops which are richest in starch or sugar, are most benefited by potash fertilization.... By facilitating the formation of starch, potash fertilizers produce a grain which is much better nourished, much larger and much heavier.... Besides, crops fertilized with potash mature at least a week earlier.... Further, the potash fertilizers play a very important part in rendering the crop resistant against the attacks of diseases and insects."

One of the most important practical results quoted by Professor Farges is, that potash is highly profitable even on soils that are naturally very rich in potash. On a soil containing as much as 1.2 per cent of acid soluble potash marvelous results were gotten by Mr. Isman, professor of Agriculture at Sidi-Bel-Abbes, Algiers, by the use of potash fertilizers.

As a further proof for the fact that potash fertilizers are highly profitable under dry farming conditions we present below another table showing the results of a few among the 100 or more tests carried out in countries as far removed from each other and from this country as New South Wales, North Africa and Peru. It will not be necessary to discuss these results in detail since the table and especially the last column of the same, giving the net profits due to potash, speaks for itself. 


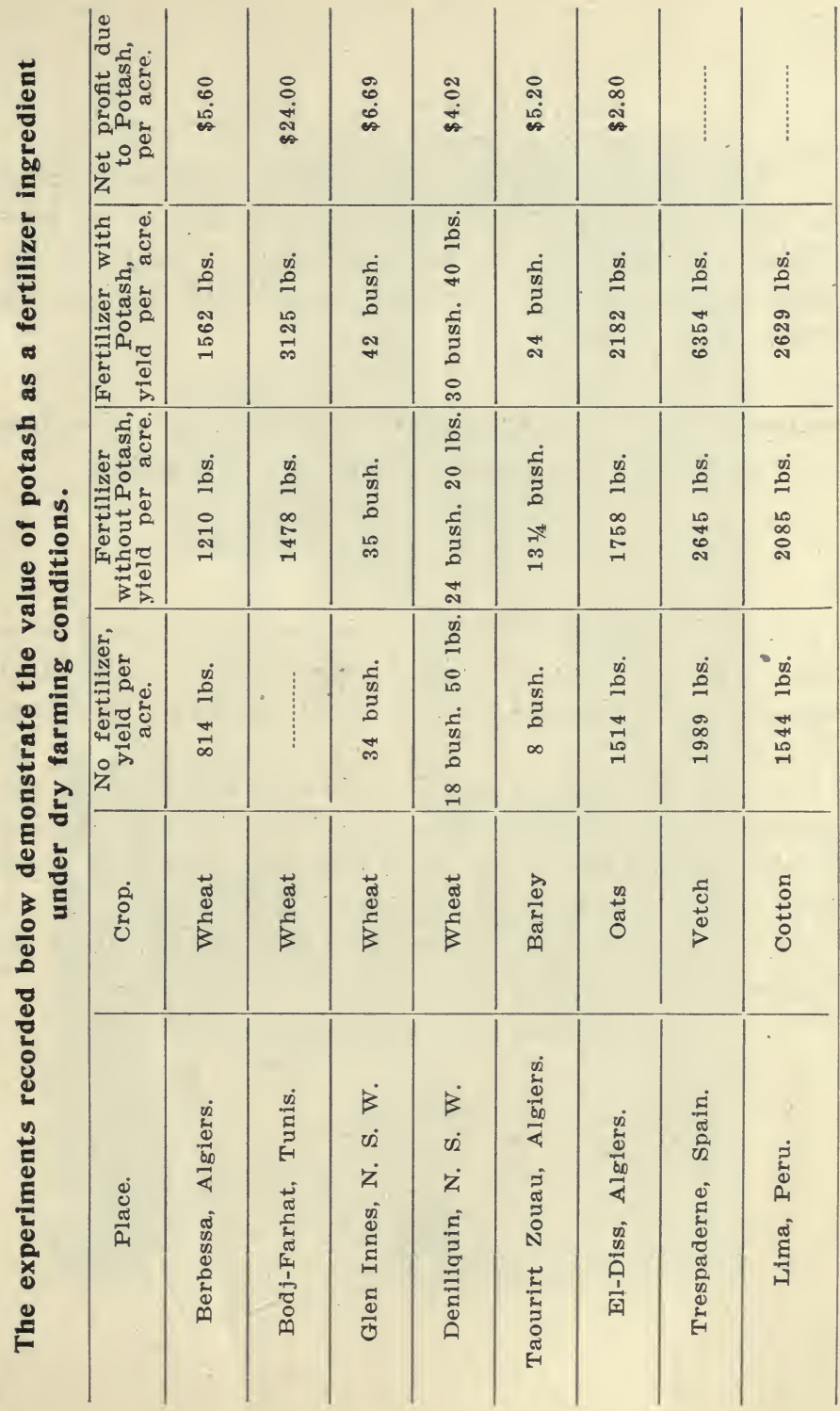


'These figures ought to convince every western farmer, that it is not only necessary, but highly profitable to use commercial fertilizers with a high percentage of potash in the districts of low rainfall. A trial by yourself will convince you better. Start it now.

\section{Summary of Advantages to Be Derived From the Use of Potash Fertilizers Under Dry Farming Conditions.}

1. With the use of potash it is possible to produce a larger quantity of grain which is thicker and heavier than when no potash is used; hence larger yields per acre and better quality.

2. Potash produces drouth resistance and decreases the quantity of the water necessary for raising the crop. Owing to this fact the culture of grain can be extended to dryer districts than it were possible otherwise.

3. Potash produces resistance against the attacks of diseases and insects.

4. Potash produces early maturity of grain crops. 


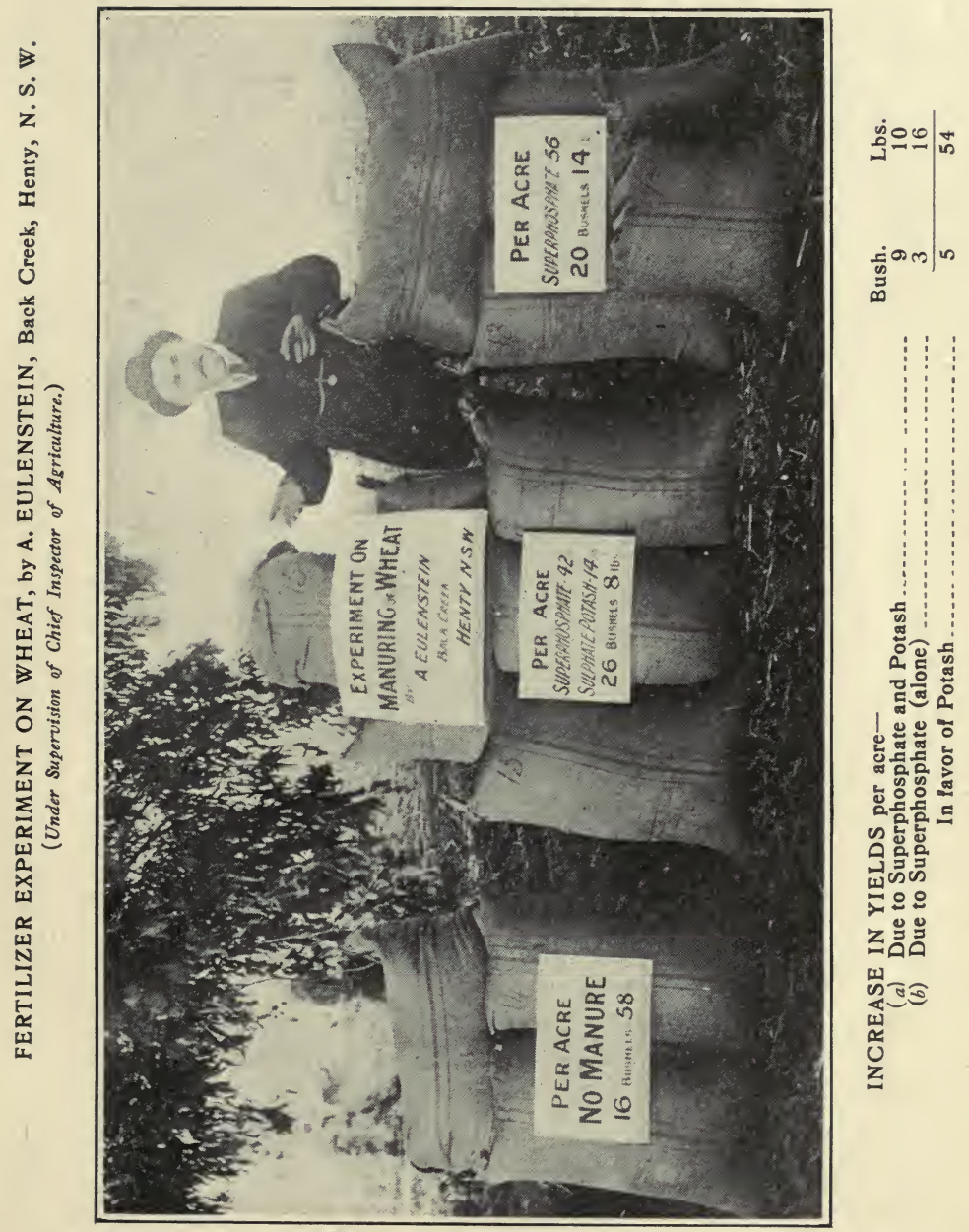




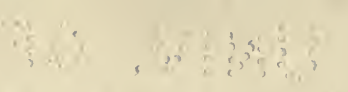

sosmon on 




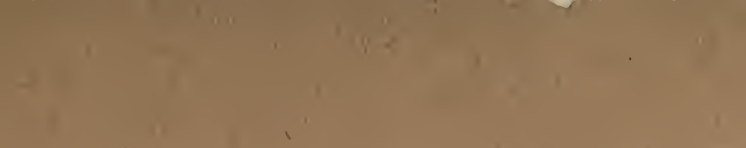

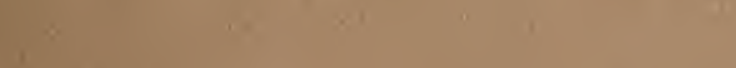

I.

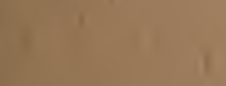

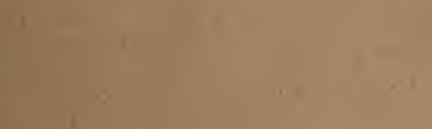

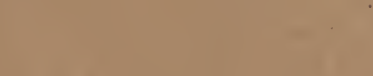




THIS BOOK IS DUE ON THE LAST DATE STAMPED BELOW

AN INITIAL FINE OF 25 CENTS WILL BE ASSESSED FOR FAILURE TO RETURN THIS BOOK ON THE DATE DUE. THE PENALTY WILL INCREASE TO 50 CENTS ON THE FOURTH DAY AND TO \$1.00 ON THE SEVENTH DAY OVERDUE.

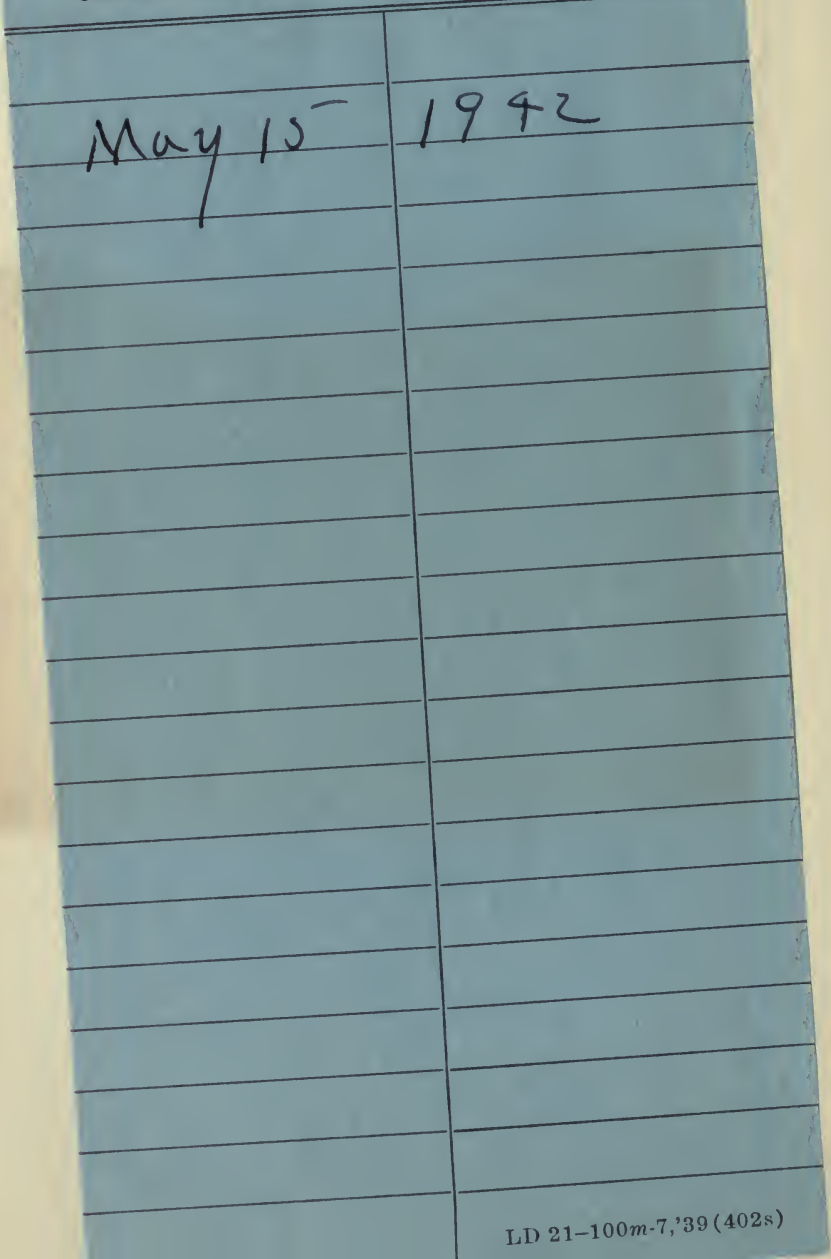


YB 16462

+2)

\section{1}

$=4$
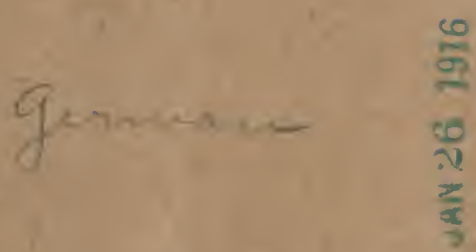

\section{UNIVERSITY OF CALIFORNIA LIBRARY}


